\title{
El desplazamiento forzado interno en México y la ineficacia de las normas de protección
}

\section{Internal forced displacement in Mexico and the innefficacy of rules protection}

DOI: https://doi.org/10.29166/tyc.v1i19.2070

\section{Hugo Martínez Montoya}

Maestro en Administración Pública por la Universidad Autónoma de Chihuahua. Actualmente se desempeña como Visitador Adjunto de la Quinta Visitaduría General de la Comisión Nacional de los Derechos Humanos (CNDH) en México.

Correo: hugomartinezmontoya@gmail.com

\section{Resumen}

El desplazamiento forzado interno en México, como consecuencia de la violencia generalizada y los conflictos generados por el control que ejerce el crimen organizado, es un problema que se ha incrementado con el paso del tiempo. Esta incidencia crimina que desplaza familias enteras, se ha fortalecido por la inacción de la administración pública. La ausencia de políticas públicas por parte del Estado ha provocado un éxodo forzado colectivo en la entidad federativa de Guerrero. Este artículo trata uno de los temas más importantes en la sociedad fronteriza del norte de México. .

Palabras clave: desplazamiento forzado, violencia, migración, políticas públicas.

\section{Abstract}

Internal forced migration in Mexico, as a consequence of widespread violence and conflicts generated by the control exercised by organized crime, is a problem that has increased over time. This criminal incident that moves away entire families has been strengthened by the inaction of the public administration. The public policies absence by the State has caused a collective forced exodus in the federal entity of "Guerrero". This article deals with one of the most important issues in the border society of northern Mexico.

Keywords: forced displacement, violence, migration, public policies. 


\section{Introducción}

A partir del 2018, México ha sido testigo de migraciones masivas y colectivas. Este fenómeno ha hecho visibles a personas que, en su mayoría, acompañadas de sus familias, se han visto impelidas a huir de situaciones de pobreza, violencia y persecución. Este padecimiento ocurre tanto en el llamado triángulo norte de Centroamérica, así como en países caribeños. No obstante, son las familias mexicanas quienes, a causa de la violencia generalizada que se experimenta en el Estado de Guerrero, se han sumado a este éxodo en un contexto de desplazamiento forzado interno (DFI).

Es Ciudad Juárez, Chihuahua, urbe fronteriza con El Paso, Texas, de los Estados Unidos de América, la que actualmente funge como espacio de acogida y tránsito de personas con necesidades de protección internacional por ser refugiadas y desplazadas forzadas internas. De acuerdo con cifras del Consejo Estatal de Población (COESPO) de Chihuahua, 18.878 personas sujetas a la protección internacional se encuentran registradas para ser llamadas por la Oficina de Aduanas y Protección Fronteriza de los Estados Unidos de América. Esta cifra comprende a quienes se registraron ante este Consejo Estatal del 27 de octubre de 2018 al 24 de septiembre de 2019.

En este artículo se expone la situación de personas de nacionalidad mexicana que se encontraban alojadas en un albergue de asistencia humanitaria de Ciudad Juárez, Chihuahua, todas originarias del Estado de Guerrero, que han tenido que huir por causa de la violencia en su lugar de residencia. Este trabajo presenta también un panorama mundial, na-

72 - Noviembre 2019 - Abril 2020 cional y local acerca de los desplazamientos forzados, que tienen características en común, como la violencia generalizada, la pobreza y la inacción por parte de los gobiernos, que tienen la obligación de actuar ante el flagelo del desarraigo y el abandono.

Por lo anterior, y sobre la base de los instrumentos jurídicos vigentes, aquí se expone acerca de la adopción y retos, en lo global; de los Principios Rectores de los Desplazamientos Internos, en lo regional; y de la Ley Número 487 para Prevenir y Atender el Desplazamiento Interno en el Estado de Guerrero, en lo local. Además, se presentan las causas que llevan a personas originarias del Estado de Guerrero a dejar su lugar de origen.

El panorama, los instrumentos jurídicos y las causas expuestas por las víctimas evidencian la falta de diligencia del Estado, específicamente en la inaplicabilidad de la norma específica que, por su creación y adopción, obliga al estado a proporcionar atención y protección a las personas víctimas del desplazamiento forzado interno.

Para realizar esta investigación fue indispensable explorar diversas leyes sobre desplazamiento forzado interno, así como su adopción en el ámbito global, regional y local. Se contó con la valiosa participación de un grupo de personas originarias de Guerrero, que voluntariamente proporcionaron al autor información mediante entrevistas respecto de lo vivido como víctimas del desplazamiento forzado interno. Además, con la finalidad de conocer las deficiencias de la administración pública, se usó el sistema de acceso a la información pública, mediante la plataforma Infomex del Instituto Nacional de Acceso a la Información (INAI). 


\section{Panorama de los desplazamientos forzados internos}

De acuerdo con el Informe presentado en Ginebra por el Observatorio de Desplazamiento Interno (IDMC), a finales del 2018, el número de personas que viven en situación de desplazamiento interno en todo el mundo, por causas de violencia y conflictos, fue de 41,3 millones. Esta cifra rebasó, con un millón, al año anterior, lo que refleja que los desplazamientos forzados internos no están siendo prevenidos por las administraciones públicas de los Estados (Observatorio de Desplazamiento Interno, 2019).

A esto, México experimenta toda clase de violencias, que van desde la estadual-institucional; social-colectiva; familiar e individual. Por ello, se puede constatar cómo emergen expresiones de violencia: despojos territoriales, extorsiones por parte del crimen organizado, con anuencia y/o participación de servidores públicos, amenazas y asesinatos $\mathrm{y}$, por ende, desplazamientos forzados internos.

De acuerdo con la Comisión Nacional de los Derechos Humanos (2016), el DFI no es un problema reciente en México. Dentro de los principales sucesos que le anteceden se encuentra el levantamiento armado del Ejército Zapatista de Liberación Nacional (EZLN), que se registró el primer día de enero de1994; la expulsión de más de treinta mil personas de adscripción tzotzil que, por razones de violencia religiosa, fueron desterradas del municipio de San Juan Chamula, Chiapas; desplazamientos por desastres natu- rales; violencia generalizada por enfrentamientos entre grupos del crimen organizado; creación de grupos de civiles armados, conocidos como "autodefensas", entre otros. En el estado de Guerrero, de acuerdo con Gómez-Johnson (2015:203), entre los años 2013 y 2014 se registraron 4.000 personas víctimas del DFI.

\section{La adopción de instrumentos jurídicos en el ámbito global, regional y local}

El tema del desplazamiento forzado interno ha sido considerado en diversos diálogos a nivel internacional. Así, como antecedente normativo, existen los "Principios Rectores de los Desplazamientos Internos". Esta norma surge el $11 \mathrm{de}$ febrero de 1998, cuando fue aprobada por la Asamblea General de Naciones Unidas para proteger a las víctimas de los desplazamientos forzados. Ahí se buscó que los estados, a través de su administración pública, garantizaran y protegieran los derechos humanos de las personas que, por situaciones de conflicto armado, violencia generalizada, violaciones a sus derechos humanos, catástrofes naturales o provocadas por el ser humano, hayan tenido que huir para salvar su integridad física, patrimonio e incluso la vida de manera individual, familiar o colectiva (Principios Rectores de los Desplazamientos Internos, 2016).

Este instrumento jurídico es un esquema orientador, pero no vinculante. Conmina $^{1}$ a los estados a proteger y proporcionar asistencia humanitaria a las

1 Sólo logra conminar, esto porque el instrumento no tiene efectos legalmente vinculantes con los Estados miembros de Naciones Unidas, sin embargo, es valioso para construir normatividad interna en los Estados y así lograr un esquema legal que atienda tal flagelo. 
víctimas de desplazamiento forzado interno durante el desplazamiento, el retorno, el reasentamiento y la reintegración, hasta que cesen las condiciones que originaron el desplazamiento.

$\mathrm{Al}$ ser insuficientes los Principios Rectores -debido la no vinculación jurídica-, en la Ciudad de Kampala, capital de Uganda, el 22 de octubre de 2009 la Cumbre Extraordinaria de la Unión Africana adopta la Convención de la Unión Africana para la Protección y la Asistencia de los Desplazados Internos en África, mejor conocida como Convención de Kampala.

Este instrumento regional africano surte efectos legalmente vinculantes respecto de los estados firmantes. Tiene, dentro de sus fines, lograr que los estados protejan y proporcionen asistencia humanitaria a las personas y/o grupos de personas desplazadas forzadas internas, por causa de conflictos armados, desastres naturales, situaciones de violencia generalizada o de violaciones de los derechos humanos (Convención de la Unión Africana para la Protección y la Asistencia de los Desplazados Internos en África, 2009).

Según el CIRC (2016), el marco jurídico integral de la Convención de Kampala aborda las necesidades de protección y asistencia a las personas víctimas del DFI. Sin embargo, refiere que los Estados, mediante una forma metódica e integral, deben prevenir y reducir los desplazamientos $\mathrm{y}$, cuando sea detectado un evento de esta envergadura, deben brindar asistencia a las víctimas y ofrecer atención con respeto a su dignidad y derechos humanos.

Este organismo internacional, emitió una serie de recomendaciones, entre las que destaca la importancia de que los Estados y demás actores dialoguen con las comunidades afectadas, con la finalidad de garantizar la participación de las víctimas en la toma de decisiones. Por ejemplo, en lo relacionado con políticas públicas, reformas y adiciones de ley, así como mecanismos de acceso a la educación y a la salud.

Países latinoamericanos, como Colombia y México, así como otros de la región, experimentan desplazamientos forzados internos. Pese a ello, no se ha logrado que la Organización de Estados Americanos adopte un instrumento con las características de la Convención de Kampala.

México es un país organizado como una república federal y cuenta con un marco jurídico federal, local y municipal. Sin embargo, dentro de las asignaturas legislativas pendientes se encuentra un vacío en el ámbito federal. Esta anomia en materia de prevención, protección y asistencia a personas víctimas de DFI lleva a la inacción por parte del Estado Mexicano, aun cuando la Organización de Estados Americanos ha instado a todos los miembros del Sistema Interamericano a incluir en su agenda programas y políticas públicas que atiendan las necesidades de esta población, con énfasis en los medios de subsistencia y en el riesgo que padecen las víctimas (Desplazados Internos, 2014).

En este tenor, sólo los estados mexicanos de Chiapas y Guerrero cuentan con legislaciones para prevenir, atender y proteger a las personas cuando son víctimas del desplazamiento forzado interno. En la entidad federativa de Guerrero, debido a los fenómenos naturales, como sismos de gran magnitud y huracanes, así como disputas agrarias, conflictos armados y el contexto de la violencia, el 22 de julio de 2014, se publicó en el Periódico Oficial del Estado de Guerrero la Ley Nú- 
mero 487 para Prevenir y Atender el Desplazamiento Interno en el Estado de Guerrero (Ley Número 487 para Prevenir y Atender del Desplazamiento Interno en el Estado de Guerrero, 2014).

En opinión de Orchard (2018:11), existen tres explicaciones posibles para el fracaso en la implementación de una ley que prevenga el desplazamiento forzado o lo atienda adecuadamente cuando este ocurra. La primera, cuando la administración pública se compromete a crear la norma, pero resulta incapaz de progresar en su implementación; la segunda, cuando el gobierno, preocupado por su reputación, decide llevar a cabo solo un compromiso de carácter retórico, estratégico, sin un verdadero plan para su implementación; y la tercera, cuando el Estado se limita a responder a las iniciativas de la sociedad civil u organizaciones no gubernamentales.

Por ello, la implementación de la Ley 487 está destinada a fracasar en sus fines. Lo anterior se puede dar cuenta mediante la respuesta que se obtuvo a través de una solicitud de transparencia a la Secretaría General de Gobierno del Estado de Guerrero, respecto de la creación del Fondo Estatal de Contingencia a cinco años de la Ley 487. Al respecto la entidad informó, mediante la plataforma de transparencia Infomex ${ }^{2}$, que aún no ha sido creado el Fondo. Esta omisión e incumplimiento legal por parte de las autoridades guerrerenses deja ver la falta de compromiso que tiene la administración pública con las personas víctimas del desplazamiento forzado interno, toda vez que se violenta el derecho a una reparación integral para las víctimas (Secretaría General de Gobierno del Estado de Guerrero, 2019).

En ausencia del Fondo Estatal de Contingencia, los municipios de Guerrero, que sufren la falta de recursos económicos, no han logrado responder ante los eventos de desplazamientos masivos. Ese es el caso de la administración pública del Ayuntamiento Municipal de Zitlala, que informa mediante su plataforma de transparencia Infomex ${ }^{3}$, que “...el Municipio no cuenta con el presupuesto necesario para poder hacerle frente al problema de las personas desplazadas, ya que el número de habitantes es sin duda numeroso..." (Ayuntamiento Municipal de Zitlala, Guerrero, 2019).

El Municipio de Leonardo Bravo, ante la incapacidad de atender el fenómeno del DFI, solicitó al presidente López Obrador, al gobernador Astudillo Flores, al diputado Sandoval Ballesteros y a la diputada Zamora Villalba la intervención urgente en el fenómeno del desplazamiento forzado (Ayuntamiento de Leonardo Bravo, Guerrero, 2019).

\section{Eventos de desplazamiento forzado en el Es- tado de Guerrero}

Según la Comisión Mexicana de Defensa y Promoción de los Derechos Humanos, A.C., (2018), en el 2017 se registraron siete episodios de desplazamiento forzado en el Estado de Guerrero. Menciona que ocurrieron en los municipios de Ajuchitán del Progreso, Chilpancingo de los Bravo, Chilapa de Álvarez, Zitlala, San Miguel Totolapan, Teloloa-

\footnotetext{
2 Oficio de respuesta DADH-157/2019, correspondiente a la solicitud de información o0130019, del 20 de marzo de 2019.
}

3 Oficio de respuesta 57/2018-2021, correspondiente a la solicitud de información o0131119, del 26 de febrero de 2019. 
pan, general Heliodoro Castillo y algunas zonas serranas y costeras. Este fenómeno provocó que 5.948 personas tuvieran que salir huyendo de su lugar de residencia. Las causas de este desplazamiento forzado se vinculan con la violencia que ejerce el crimen organizado, las autodefensas y el narcotráfico.

En este contexto y a partir de las obligaciones de la administración pública en la prevención, atención y protección a víctimas, se dirigieron solicitudes de transparencia a diversos municipios del Estado de Guerrero. Se obtuvo que, en el caso del Municipio de Teloloapan, la Dirección de Protección Civil reconoció, a través de la plataforma de transparencia Infomex 4 , que en esa localidad hubo desplazamientos forzados de personas entre 2016 al 2019. Sin embargo, asegura no haber tenido recursos económicos para atender la contingencia. Además, refiere que no tiene programas de prevención y atención para garantizar los derechos humanos de las víctimas (Protección Civil del Municipio de Teloloapan, Guerrero, 2019).

En el Municipio de Coyuca de Catalán, en el 2016, se suscitó un conflicto en la comunidad de Los Ciruelos, motivo por el cual se desplazaron forzadamente 22 familias. Además, en el 2018 la formación de un socavón en la comunidad de Pinzan Morado desplazó a 27 familias y dos instituciones educativas. Por ello, la administración pública del Municipio de Coyuca de Catalán solicitó a la Secretaría de Protección Civil del Estado de Guerrero que interviniera. Esto porque la capacidad de respuesta del Ayuntamiento fue insuficiente (Ayuntamiento Municipal Coyuca de Catalán, 2019).

\section{Las personas desplazadas desde el Estado de Guerrero hacia Ciudad Juárez.}

De acuerdo con datos proporcionados por COESPO, entre junio y septiembre de 2019 se ha identificado a 365 personas, la mayoría acompañadas por sus familias, originarias del estado de Guerrero, que se encuentran en los cruces internacionales fronterizos de Ciudad Juárez, Chihuahua, hacia El Paso, Texas, con intenciones de solicitar la protección internacional de asilo al gobierno estadounidense.

Según Levinas (2017:59), cuando "el otro" se manifiesta en el rostro, se logra que ellas y ellos se perciban y, por ende, reconozcan mediante sus rostros los conflictos de violencia que actualmente provoca en los guerrerenses un estado de indefensión y un estatus de ciudadanos sin derechos. Por ello, aquí hacemos un acercamiento a las personas desplazadas forzadamente que han arribado a Ciudad Juárez, Chihuahua. Esta aproximación busca identificar en las personas desplazadas, sus necesidades humanitarias y de protección.

Respecto a los motivos para migrar, se encontró que el 84\% huye de la violencia e inseguridad de su lugar de origen y manifiesta un temor fundado ${ }^{5}$. No obstante, un 8\% dijo estar padeciendo amenazas y extorsiones por parte de grupos del crimen organizado. Además, el $8 \%$ manifestó sufrir violencia familiar, (véase figura 1).

\footnotetext{
Oficio de respuesta 0125/MARZO/2019, correspondiente a la solicitud de información 00130919, del 26 de febrero de 2019.

5 Es importante comentar que esta población refiere temor por ser ultimada y dicen no estar dispuestos ya a estar inmersos en la zozobra y el miedo.
} 


\section{Figura 1. Causas del desplazamiento forzado interno de personas originarias del Estado de Guerrero (Porcentajes)}

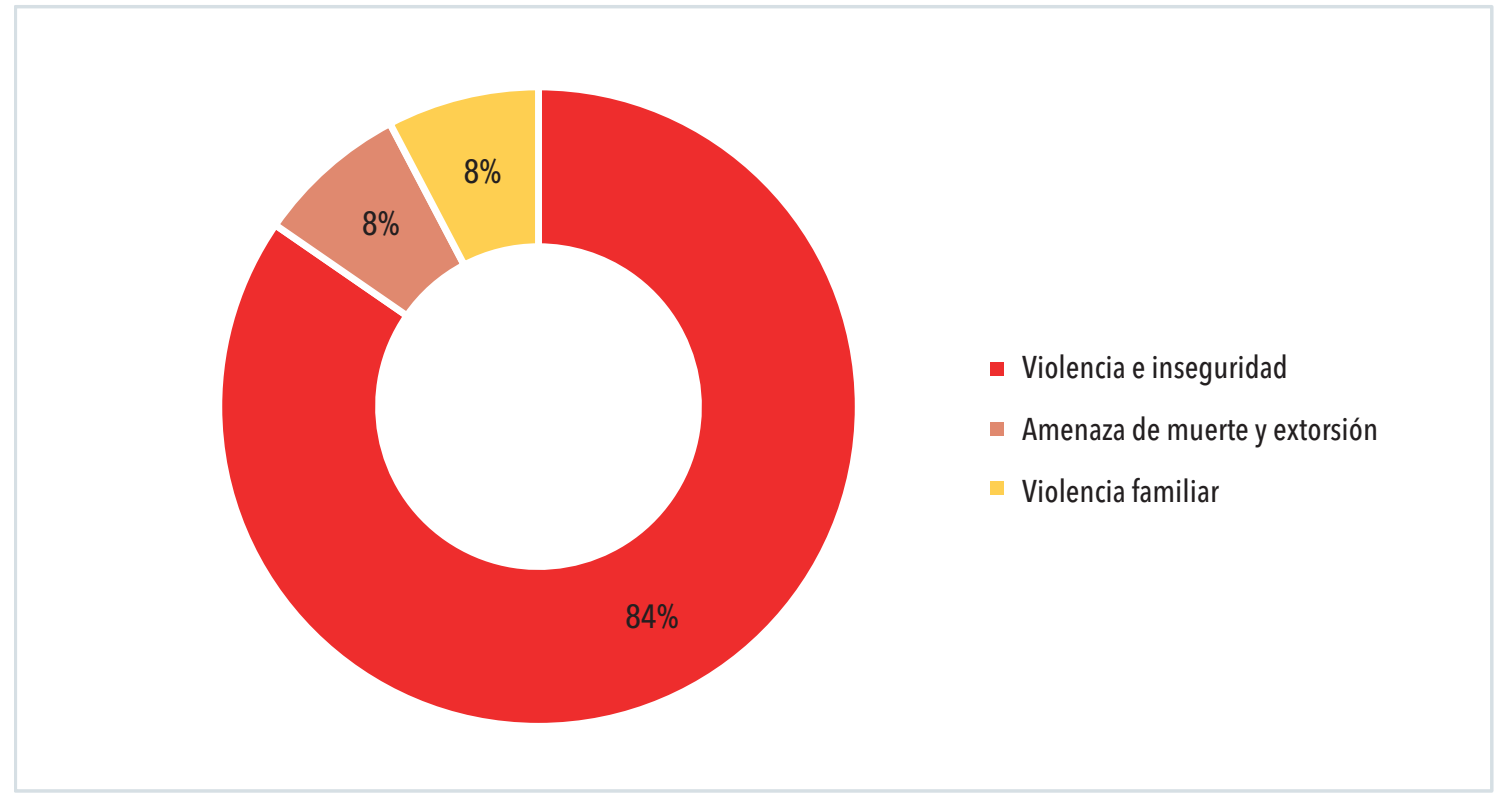

Fuente: Elaboración propia a partir de la aplicación de entrevistas a personas alojadas en la Casa del Migrante en Juárez, A.C. ${ }^{6}$

La escolaridad promedio de las personas entrevistadas corresponde a primaria y secundaria, lo que las coloca en un estado de precariedad respecto del acceso a la educación, considerando que las edades de las y los entrevistados se encuentran entre los 17 y 39 años. Respecto de la ocupación que desarrollaban antes de sufrir el desplazamiento, en el caso de los hombres, tejían y cocían con aguja balones de futbol soccer y labores asalariadas en el campo agrícola; en el caso de las mujeres, desarrollaban mayormente actividades del hogar, dato que evidencia ingresos precarios.
Del universo de personas identificadas como desplazadas, el $78 \%$ salió huyendo con su familia y el $14 \%$ sin compañía. Además, todas y todos manifestaron que se dirigían a los Estados Unidos de América. A pregunta expresa, el $39 \%$ aseguró no conocer el procedimiento de solicitud de asilo ante autoridades norteamericanas, lo que coloca a casi 4 de cada 10 solicitantes de la protección internacional en una negativa anunciada o situación previa de rechazo.

Es importante mencionar que las personas que solicitan la protección internacional a los Estados Unidos necesitan

6 Las entrevistas se realizaron en un albergue de asistencia humanitaria especializada en personas en el contexto de la movilidad humana, utilizando para ello, la aplicación de entrevistas individuales, en las cuales se buscó que las preguntas fueran las adecuadas para poder describir las características de las y los entrevistados. Se logró entrevistar a 14 personas en el período del 7 de marzo al 6 de junio del 2019. El tamaño de la muestra correspondió a tres hombres y 11 mujeres, originarios de las comunidades de Chichihualco, Municipio de Coyuca de Catalán, Tlacotepec, Municipio General Heliodoro Castillo, Eduardo Neri, Chilpancingo, Leonardo Bravo y Acapulco. 
conocer que personal del Servicio de Inmigración y Control de Aduanas (ICE, por sus siglas en inglés), formulará preguntas para verificar el "temor creíble" de persecución, lo que implica que en esa entrevista el solicitante deberá demostrar que tiene temor fundado de que, si es retornado a su lugar de origen, será perseguido o torturado por motivos de raza, convicción religiosa, nacionalidad, ser miembro de un grupo social muy específico u opinión política.

Según datos del Instituto Nacional de Estadística y Geografía, INEGI
(2019), la incidencia delictiva en el Estado de Guerrero por cada cien mil habitantes, entre 2014 y 2017, ha estado por encima de la tasa por país. Esto muestra que los eventos documentados respecto a la comisión del delito rebasan el promedio de la suma de las 32 entidades federativas $y$, por ende, cataloga al Estado de Guerrero como uno de los más violentos, por lo que se puede establecer una correlación entre la violencia y los desplazamientos (véase figura 2).

Figura 2. Tasa de incidencia delictiva por entidad federativa por cada cien mil habitantes.

60.000

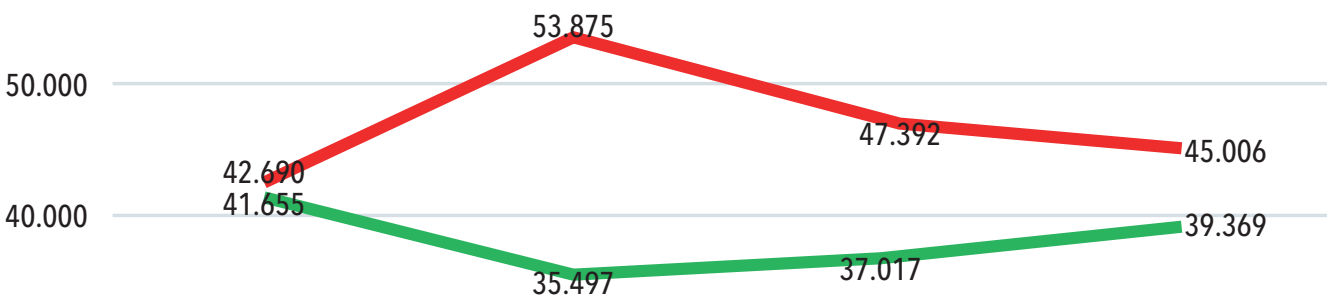

30.000

20.000

10.000

0
2015
2016
2017

Estados Unidos Mexicanos

Guerrero

:uente: Elaboración propia a partir de Instituto Nacional de Estadística y Geografía (2019). 
Puesto que la violencia y la inseguridad son las principales causas que refieren las personas entrevistadas, es necesario mencionar que los problemas de inseguridad, aunados con la impunidad, detonan de manera directa este flagelo. Ahora, respecto de las posibles soluciones a los desplazamientos forzados de las personas originarias del Estado de Guerrero, que arriban a Ciudad Juárez, Chihuahua, es posible, a partir de la consulta a las mismas víctimas, proponer la reintegración al lugar de origen, lo que comprometería a la entidad federativa expulsora a generar un contexto de paz y desarrollo para todas y todos.

Por otro lado, el derecho que asiste a las víctimas a la integración, en este caso, en Ciudad Juárez, Chihuahua, implica para la entidad federativa de Chihuahua que se establezcan lugares de asentamiento con garantías de desarrollo y sostenibilidad. A todo esto, no está demás referir que las condiciones de desarrollo que aquí se aluden incluyen acceso a la educación, salud, empleo, alimentación, vivienda digna, seguridad pública, etc. (ACNUR, 2011).

Aunado a lo anterior, las víctimas del DFI pueden estar expuestas a sufrir discriminación en el proceso migratorio, por lo que tal revictimización podría presentarse en el lugar de acogida como asimilación forzada, empleos precarizados, ausencia de un modelo de inserción integral, afectaciones psicosociales derivadas del trauma sufrido, efectos económicos por haber abandonado sus propiedades, entre otras secuelas del DFI.

\section{Conclusiones}

La falta de protección de la administración pública en los lugares de origen y/o residencia de quienes se han visto impelidos a migrar, los desarraiga y diluye la unidad cohesionada que deben mantener las estructuras estatales y las personas titulares de derechos. En ese contexto, la cultura y tradiciones son llevadas en el trasiego por parte de las personas expulsadas, en un suplicio que representa esa última esperanza de encontrar un territorio donde el asentamiento ofrezca seguridad y desarrollo. Después, tienen que crear un nuevo vínculo donde nada les pertenece y son vistas como personas sin derechos, sin un sentido de pertenencia y, por ende, sin Estado.

De acuerdo con Arendt (1998:237), para las personas sin Estado no existe un espacio apropiado en el marco de las leyes generales. Por ello, las víctimas del DFI, aunque son ciudadanos y ciudadanas, se encuentran en una dicotomía, porque fungen como extranjeros en su propio lugar de origen. Por lo tanto, no son sujetos de deportación ni de protección y se acercan más a la figura del apátrida.

En el Estado de Guerrero, México, los conflictos se incrementan, la inseguridad agrava la intensidad de la violencia pública y el índice de delitos continúa en ascenso, No hay razones para pensar que los desplazamientos forzados vayan a cesar. Es verdad que se puede aprender de las medidas que se han tomado en países como Colombia7 $^{7}$, sin embargo, para abordar las causas

7 De acuerdo al ACNUR (2018), en Colombia se ha fortalecido la capacidad de respuesta a personas en riesgo del desplazamiento y se trabaja en visibilizar el impacto continuado de los conflictos y la violencia, además de robustecer la protección de víctimas del DFI. 
y efectos de los desplazamientos se requiere de políticas públicas con enfoque local, emulando buenas prácticas adecuadas a la población en específico.

El contexto de inseguridad que miles de mexicanas y mexicanos experi- mentan en el día a día nos predice que los desplazamientos forzados van a continuar. Por ello, es urgente que la administración pública reconozca el fenómeno y actúe en consecuencia, promoviendo, además, la participación de la sociedad organizada.

\section{Bibliografía}

ACNUR. (2011). Manual de Reasentamiento del ACNUR. Ginebra, Suiza: Alto Comisionado de las Naciones Unidas para los Refugiados.

ACNUR. (2018). "ACNUR en Colombia". Obtenido de https://www.acnur.org/5b97f3154.pdf

Alloatti, M. N. (s.f.). "Una discusión sobre la técnica de bola de nieve a partir de la experiencia de investigación en migraciones internacionales". Universidad Federal de Santa Catarina. Recuperado el 23 de Junio de 2019, de http://elmecs.fahce.unlp.edu.ar/iv-elmecs/AlloattiPONmesa13.pdf

Álvarez, J. L., \& Jurgenson, G. (2003). Cómo hacer investigación cualitativa. México: Paidós Mexicana, S.A.

Arendt, H. (1998). Los orígenes del totalitarismo. España: Taurus.

Ayuntamiento de Leonardo Bravo, Guerrero. (2019). Oficio UTMLB/006/2019. Respuesta a Solicitud de Transparencia, Leonardo Bravo, Guerrero.

Ayuntamiento Municipal Coyuca de Catalán. (2019). Oficio 21/2019. Respuesta a Solicitud de Transparencia, Coyuca de Catalán, Guerrero.

Ayuntamiento Municipal de Zitlala, Guerrero. (2019). Oficio 57/2018-2021. Respuesta a Solicitud de Transparencia, Zitlala, Guerrero.

CICR. (2016). Puesta en práctica de la Convención de Kampala: Ejercicio de balance. Ginebra: Comité Internacional de la Cruz Roja.

Comisión Mexicana de Defensa y Promoción de los Derechos Humanos, A.C. (2018). Episodios de Desplazamiento Interno Forzado Masivo en México, Informe 2017. Ciudad de México: Comisión Mexicana de Defensa y Promoción de los Derechos Humanos, A.C.

Comisión Nacional de los Derechos Humanos. (Mayo de 2016). Informe Especial sobre Desplazamiento Forzado Interno (DFI) en México. México.

Convención de la Unión Africana para la Protección y la Asistencia de los Desplazados Internos en África. (2009). (ACNUR, Trad.) Kampala, Uganda.

Desplazados Internos, AG7RES.2850 (XLIV-0/14) (Asamblea General de la Organización de los Estados Americanos 4 de junio de 2014). Obtenido de http://www.oas.org/es/sla/ddi/docs/AG-RES_2850_XLIV-0-14.pdf

Gómez-Johnson, C. (2015). De la migración económica a la migración forzada por el incremento de la violencia en El Salvador y México. Estudios Políticos, 199-220. 
Levinas, E. (2017). Humanismo del otro hombre. Ciudad de México: Siglo veintiuno editores.

Ley Número 487 para Prevenir y Atender del Desplazamiento Interno en el Estado de Guerrero. (2014). Chilpancingo: Periódico Oficial del Gobierno del Estado de Guerrero.

Observatorio de Desplazamiento Interno. (2019) Hay más desplazados internos que nunca antes. Ginebra: Consejo Noruego para Refugiados.

Orchard, P. (2018). "La implementación de los Principios Rectores a nivel nacional". Migraciones Forzadas, 10-12.

"Principios Rectores de los Desplazamientos Internos". (2016). Consejo Noruego para Refugiados y la Alto Comisionado de las Naciones Unidas para los Refugiados. Obtenido de http://www.nrc.org.co/wp-content/uploads/2017/07/Principios_rectores_desplazamiento_NRC.pdf

Protección Civil del Municipio de Teloloapan, Guerrero. (2019). Oficio 0125/MARZO/2019. Respuesta a Solicitud de Transparencia, Teloloapan, Guerrero.

Secretaría General de Gobierno del Estado de Guerrero. (2019). Oficio DADH-157/2019. Respuesta a Solicitud de Transparencia, Chilpancingo, Guerrero. 